\title{
The relationship between organizational commitment and knowledge sharing: A case study of university employee cooperation
}

\author{
Hosein Bahramzadeh $^{\mathrm{a}}$ and Soheila Khosroabadi ${ }^{\mathbf{b}}$
}

${ }^{a}$ Ph.D. in Public Administration ,assistant professor and Scientific Member Azad University of Bojnourd, Bojnourd, Iran ${ }^{b}$ Master of Educational Administration, Bojnourd, Iran

\begin{tabular}{|c|c|}
\hline A R T I C L E I N F O & AB S TRACT \\
\hline $\begin{array}{l}\text { Article history: } \\
\text { Received March 29, } 2012 \\
\text { Received in Revised form } \\
\text { June, 12, } 2012 \\
\text { Accepted } 19 \text { June } 2012 \\
\text { Available online } \\
\text { June } 262012 \\
\text { Keywords: } \\
\text { Econometrics } \\
\text { Banking system } \\
\text { Profitability } \\
\text { Return on Asset }\end{array}$ & $\begin{array}{l}\text { Knowledge sharing plays an important role on helping organizations reach their goals, it } \\
\text { facilitates distribution of overall awareness among workers and create better environment for } \\
\text { adding more value. There are different factors influencing knowledge sharing and } \\
\text { organizational commitment is believed one of the most important items. In this paper, we } \\
\text { present an empirical study in one of privately held universities located in city of Bojnourd, Iran. } \\
\text { The proposed study selects a sample size } 145 \text { out of } 236 \text { people from both regular employees } \\
\text { and university professors and we have used different tests such as Pearson correlation test to } \\
\text { analyze the results. The proposed model of the paper has confirmed that there is a positive and } \\
\text { meaningful relationship between these two components when the level of significance is set to } \\
\text { five percent. The results of this survey also reveals that while ethical commitment and } \\
\text { normative play important role on knowledge sharing, continuity has no significant impact on } \\
\text { knowledge sharing within organization. The other observation is that while gender and age has } \\
\text { no impact on knowledge sharing, higher educational background is an important factor on } \\
\text { knowledge sharing. }\end{array}$ \\
\hline
\end{tabular}

\section{Introduction}

Knowledge sharing (KS) plays an important role on increasing organizational efficiency. It can help members of an organizational learn more, improve their skills and become more professional (Alvesson, 2000; Alavi \& Leidner, 2001; Stride et al., 2007). However, there is a problem when some people are not interested in sharing their knowledge for different reasons such as lack of confidence on job security, lack of trust to others, etc. Panteli and Sockalingam (2005) investigated the impact of trust and conflict within virtual inter-organizational alliances in a framework for facilitating KS. Elias (2005) The effect of corporate ethical values on accountants’ perceptions Of social responsibility. 
Bandyopadhyay and Pathak (2007) investigated the relationship between KS and cooperation in outsourcing projects using game theory analysis. Their analysis indicated that when the degree of complementarity of knowledge between the employees is high enough, better payoffs can be achieved whenever the top management enforces cooperation among the employees. In these situations, the engagement of the top management extends far beyond negotiating the contract to make the outsourcing successful.

Today, many organizations have realized that knowledge constitutes a valuable asset to create and to sustain competitive advantages (Miller \& Shamsie, 1996). KS activities are globally accepted by most knowledge management systems. However, technology includes only one of the most important factors, which influences the sharing of knowledge in organizations. There are other requirements needed such as organizational culture, trust, and incentives (Cabrera \& Cabrera, 2002). The sharing of knowledge includes a major challenge in the field of knowledge management since there are always some employees who resist sharing their knowledge with the rest of the organization.

One important barrier is the notion that knowledge is property and ownership thus is very important and to remove such obstacle, individuals must be informed that they would receive some type of incentive for what they generate. However, Dalkir (2005) determined that the risk in KS is that individuals are most commonly rewarded for what they know, not what they share. Once knowledge is not shared, negative outcomes such as isolation and resistance to ideas will definitely happen. Shared knowledge helps different viewpoints and possible solutions to different problems. To promote KS and to remove its obstacles, the organizational culture should facilitate discovery and innovation, which helps creation of organizational culture.

Renzl (2008) investigated the relationship between trust and knowledge sharing. He explained that KS plays an important role for organizations and the impact of interpersonal trust in general and more specifically trust in management on KS is evident. However, it is not easy to understand how the relationship between interpersonal trust and KS works. He performed a comprehensive study on the that relationship by examining whether the fear of losing one's unique value and knowledge documentation had a mediating impact on the relationship between trust in management and KS. More specifically, trust in management increases KS through reducing fear of losing one's unique value and improving willingness to document knowledge and this is important different places.

Lin (2008) investigated on three factors influencing KS within an organization including organizational structure characteristics, organizational culture and interunit interactions. Lin (2008) used linear fuzzy neural network to find out the lower formalization of an organizational structure. Based on the results of Lin (2008), the lower the formalization of an organization, the greater the KS among units of an organization will be. On the other hand, the results also reveal that trust and commitment among units are vital for facilitating KS among units and creative and supporting conditions of organizational culture contribute adaptation of KS within an organization.

Chen and Hung (2010) explained that to promote KS, it is necessary to know why individuals select to give or to receive knowledge with other community members and identified important influential factors in increasing community knowledge transfer and investigated their effects in professional virtual communities (PVC)s. They gathered some data from 323 members of two communities and implemented a structural equation modeling (SEM) to analyze the data. The results recommended that norm of reciprocity, interpersonal trust, KS self-efficacy, and perceived relative advantage played essential role on KS behaviors in PVCs. The knowledge contributing and collecting behaviors were positively associated with knowledge utilization.

Dawes et al. (2012) explained that information, KS and practices across cultural and national boundaries are important tools to address critical global problems. These days, even many governmental agencies substantially cooperate with international counterparts on different issues, transnational knowledge and KS networks rapidly grow as tools for collaboration. They investigated 
the nature of transnational public sector knowledge networks (TPSKNs) and determined critical contextual parameters, which shape their performance. In such networks, each participating organization acts within complex national, organizational, and information contexts. The contextual changes among participants generate distances in culture, politics, intentions, relationships, knowledge, resources, organizational factors, geography, and technology. These distances impact their capabilities to involve in the processes and interactions, which are necessary to network performance. They reported that accounts for the relationships among these changes, which could guide further research in understanding knowledge and information sharing across national and cultural boundaries.

In this paper, we study the relationship between organizational commitment and knowledge sharing for one of private universities located in west part of Iran called Bojnourd University. The organization of this paper first presents the implementation of the model in section 2. Section 3 presents details of our results and concluding remarks are given in the last to summarize the contribution of the paper.

\section{The proposed study}

This is an applied research and in terms of gathering the data, it is considered as descriptive survey. The proposed survey uses two variables of organizational knowledge sharing and organizational commitment. The proposed study of this paper uses two types of questionnaires. The first questionnaire measures organizational commitment and it contains three perspectives of ethical commitment (8 questions), continuity (8 questions) and normative (8 questions). All questions are arranged in Likert scale from completely disagree to completely agree. Cronbach alpha was calculated as 0.7326 , which is above the minimum acceptable limit.

The other questionnaire is associated with organizational knowledge sharing, which consists of 10 questions and they are all designed in Likert scale from completely disagree to completely agree. Cronbach alpha was calculated as 0.82 , which is again above the minimum desirable limit. The sample size, which covers all employees and university professors of Azad University of Bojnourd is calculated using as the following,

$n=\frac{N \times z_{\alpha / 2}^{2} \times p \times q}{\varepsilon^{2} \times(N-1)+z_{\alpha / 2}^{2} \times p \times q}$,

where $N$ is the population size, $p=1-q$ represents the yes/no categories, $z_{\alpha / 2}$ is CDF of normal distribution and finally $\varepsilon$ is the error term. Since we have $p=0.5, z_{\alpha / 2}=1.96$ and $N=236$, the number of sample size is calculated as $n=145$.

\section{The results}

In this paper, we have used Pearson correlation test along with some descriptive statistics such as mean and standard deviation to verify the main hypothesis as well as the sub hypotheses of the paper.

3.1 The main hypothesis: The relationship between organizational commitment and organizational knowledge sharing

The first hypothesis of this paper considers whether there is a meaningful relationship between organizational commitment and organizational knowledge sharing. Table 1 shows Pearson correlation ratio along with other statistics. 


\section{Table 1}

The results of Pearson correlation test ratio for the main hypothesis

\begin{tabular}{lllcl}
\hline Independent variable & Dependent variable & Pearson ration & $\begin{array}{c}\text { Level of } \\
\text { significance }\end{array}$ & Results of test \\
\hline $\begin{array}{l}\text { Organizational } \\
\text { commitment }\end{array}$ & $\begin{array}{l}\text { Organizational } \\
\text { Knowledge sharing }\end{array}$ & 0.510 & 0.000 & Confirmed \\
\hline
\end{tabular}

As we can observe from the results of Table 1, there is meaningful and positive relationship between organizational commitment and organizational knowledge sharing. As we can observe from the results of Table 2 there is a positive and meaningful relationship between ethical commitment and normative as independent variables and organizational knowledge sharing and we can accept reject of null hypothesis for having no relationship when the level of significance is 0.01 . However, the null hypothesis of having no relationship between continuity and organizational knowledge sharing cannot be rejected when the level of significance is set to one or five percent.

\subsection{Testing three sub-hypotheses}

In this section we present the results of our survey on relationship between knowledge sharing with ethical commitment, continuity and normative. Table 2 shows details of our survey for this test,

\section{Table 2}

The results of Pearson correlation test ratio for the three sub-hypothesis

\begin{tabular}{llccl}
\hline Independent variable & Dependent variable & Pearson ration & $\begin{array}{c}\text { Level of } \\
\text { significance }\end{array}$ & Results of test \\
\hline Ethical commitment & $\begin{array}{l}\text { Organizational } \\
\text { Knowledge sharing }\end{array}$ & 0.583 & 0.000 & Confirmed \\
Continuity & $\begin{array}{l}\text { Organizational } \\
\text { Knowledge sharing }\end{array}$ & 0.152 & 0.12 & $\begin{array}{l}\text { Not } \\
\text { Confirmed } \\
\text { Normative }\end{array}$ \\
$\begin{array}{l}\text { Organizational } \\
\text { Knowledge sharing }\end{array}$ & 0.526 & 0.000 & Confirmed \\
\hline
\end{tabular}

\subsection{The role of gender on knowledge sharing}

In this section, we investigate whether gender has any influence on knowledge sharing by using mean difference test and the results are summarized in Table 3.

\section{Table 3}

Mean difference test for the impact of gender

\begin{tabular}{lccc}
\hline Gender & $\begin{array}{c}\text { Mean of interest in } \\
\text { knowledge sharing }\end{array}$ & $\begin{array}{c}\text { Standard deviation in } \\
\text { knowledge sharing }\end{array}$ & The significance level \\
\hline Male & 1.91 & 0.66 & 0.906 \\
Female & 1.74 & 0.58 & \\
\hline
\end{tabular}

As we can observe from the results of Table 3, gender does not play an important role on knowledge sharing and they both relatively are unwilling to share their knowledge within the organization.

\subsection{The role of job identity on knowledge sharing}

As we explained earlier, the sample size of this survey included both university professor and regular employees and it was important to understand whether job position plays and important impact on sharing the knowledge within the organization or not. Table 4 shows details of our test on this hypothesis. 
Table 4

Mean difference test for the impact of job position

\begin{tabular}{lccc}
\hline Gender & $\begin{array}{c}\text { Mean of interest in } \\
\text { knowledge sharing }\end{array}$ & $\begin{array}{c}\text { Standard deviation in } \\
\text { knowledge sharing }\end{array}$ & The significance level \\
\hline University professor & 2.51 & 2.51 & 0.03 \\
Regular staff & 1.74 & 1.74 & \\
\hline
\end{tabular}

As we can observe from the results of Table 4, there is a meaningful difference between university professors and regular employees of this university and based on the results of Table 4, university professors are willing more to share their knowledge within the organization compared with regular employees when the level of significance is three percent. We have also performed a test to see whether different people with various age characteristics have different knowledge sharing levels and the result of our survey was negative.

\section{Conclusion}

In this paper, we have presented an empirical study to investigate the relationship between organizational commitment and knowledge sharing in a private university located in east of Iran called Bojnourd Azad university. The proposed model of the paper has confirmed that there is a positive and meaningful relationship between these two components when the level of significance is set to five percent. The results of this survey revealed that while ethical commitment and normative played important role on knowledge sharing, continuity had no significant impact on knowledge sharing within organization. The other observation was that while gender and age had no impact on knowledge sharing, higher educational background was an important factor on knowledge sharing.

\section{Acknowledgment}

The authors would like to thank the officials of Islamic Azad University of Bojnourd for cordially supporting this research project.

\section{References}

Alvesson, M. (2000), Social Identity and the problem of loyalty in Knowledge-Intensive Companies. Journal of Management Studies, 37, 1101-1123.

Alavi \& Leidner, D.E.(2001), Review: Knowledge Management and Knowledge Management Systems. Conceptual Foundations and Research Issues. MIS Quarterly,25(1), 107-136.

Bandyopadhyay, S., \& Pathak, P. (2007). Knowledge sharing and cooperation in outsourcing projects - A game theoretic analysis. Decision Support Systems, 43(2), 349-358.

Cabrera, A., \& Cabrera, E. F. (2002). Knowledge-sharing Dilemmas. Organization Studies, 23 (5), 687-710.

Chen, C.J., \& Hung, S.W. (2010). To give or to receive? Factors influencing members' knowledge sharing and community promotion in professional virtual communities. Information \& Management, 47(4), 226-236.

Dawes, S.S., Gharawi, M.A., Burke, G.B. (2012). Transnational public sector knowledge networks: Knowledge and information sharing in a multi-dimensional context. Government Information Quarterly, 29(1), S112-S120.

Elias, R.Z. (2005). The effect Of corporate ethical values on accountants' perceptions Of social responsibility. The Journal of Applied Business Research, 21, 1-10 .

Lin, W. B. (2008). The effect of knowledge sharing model. Expert Systems with Applications, 34(2), 1508-1521.

Miller, D., \& Shamsie, J. (1996). The resource-based view of the firm in two environments: The Hollywood film studios from 1936 to 1965 . Academy of Management Journal, 39(3), 519-543. 
Panteli, N., \& Sockalingam, S. (2005). Trust and conflict within virtual inter-organizational alliances: a framework for facilitating knowledge sharing. Decision Support Systems, 39(4), 599-617.

Renzl,B. (2008). Trust in management and knowledge sharing: The mediating effects of fear and knowledge documentation. Omega, 36(2), 206-220.

Snowden, D. (2002). Complex acts of knowing: paradox and descriptive self-awareness. Journal of Knowledge Management, 6(2): 100-111.

Stride, C., Wall, T. D., \& Catley, N. (2007). Measures of Job Satisfaction, Organizational Commitment, Mental Health and Job Related Well-being: A Benchmarking Manual. ${ }^{\text {nd }}$ ed. John Wiley \& Sons, Ltd. 